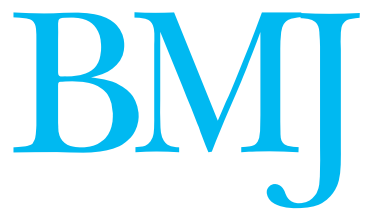

\title{
Addressing inequalities in research capacity in Africa
}

\author{
All sides in partnerships must ensure that research aims to improve the health of all
}

$\mathrm{T}$ his special theme issue includes a feast of high quality papers by African researchers on a range of topics of great relevance to health and health care in Africa. Despite our best efforts we did not achieve the geographical spread of submissions that we hoped for, mostly because we receive articles from authors in only a few African countries. We do not know the extent to which this reflects lack of research capacity or whether the prevailing political, social, and economic conditions in these countries militate against meaningful research. Whatever the reasons, the dearth of research done in Africa for Africa is untenable.

Research capacity-comprising the institutional and regulatory frameworks, infrastructure, investment, and sufficiently skilled people to conduct and publish research-varies widely across African countries. In a report to the World Bank that ranked countries according to their national investments and productivity in science and technology, South Africa, Egypt, and Mauritius did reasonably well, while the rest of Africa appeared at the bottom of the league table under "scientifically lagging countries."1 Although this generalisation obscures the fact that scientifically less advanced countries may have excellent capacity in certain niche areas, there can be no doubt that African research is moribund.

Inequalities in health research contribute to inequalities in health. If science is to live up to its promise to improve health and spur development, all countries should be able to participate in research. Research must reflect national priorities and focus particularly on conditions with high burdens in Africa's populations, on evaluating interventions that aim to strengthen health systems, and on activities to convert knowledge into action. ${ }^{2-4}$

Collaboration in research, widely represented in this theme issue, may be one vehicle for strengthening research capacity in less privileged countries. African scientists welcome collaboration with the North as a means of overcoming barriers to research and promoting exchange of ideas. Unfortunately, Africans seem less enthusiastic about collaboration between countries within their own continent. This situation may improve: the New Partnership for Africa's Development (NEPAD) is actively facilitating partnerships within Africa and with the international community. ${ }^{5}$ Given the unequal power relations between rich and poor nations, research collaboration between them poses certain risks.
Guidelines on international partnerships in research should, however, help to minimise the danger of scientific colonialism masquerading as research collaboration. $^{6-9}$

More partnerships with individuals and institutions in African countries are needed, but these should be equitable. Scientific motives and personal characteristics are not the only factors determining who collaborates with whom. Historical (often colonial) relations between countries, shared languages, and economic or security interests tend to promote contact between researchers and may provide earmarked funding for collaboration. Practical difficulties associated with countries' infrastructure, systems for information and communication, travel, foreign exchange, and safety may also influence the establishment and maintenance of scientific interaction. Such factors leave the most disadvantaged countries as the least likely to attract investment research.

The United Nation's 2005 Human Development Report noted that inequalities between and within countries are growing rapidly and that the concept of international development aid trickling down to the poorest has not worked. $^{10}$ Facilitating research partnerships that include the most disadvantaged groups will depend on targeted investments by the international community as well as by Africans. Good examples of such partnerships can be found in papers in this issue. ${ }^{11-13}$ More can be done if overall

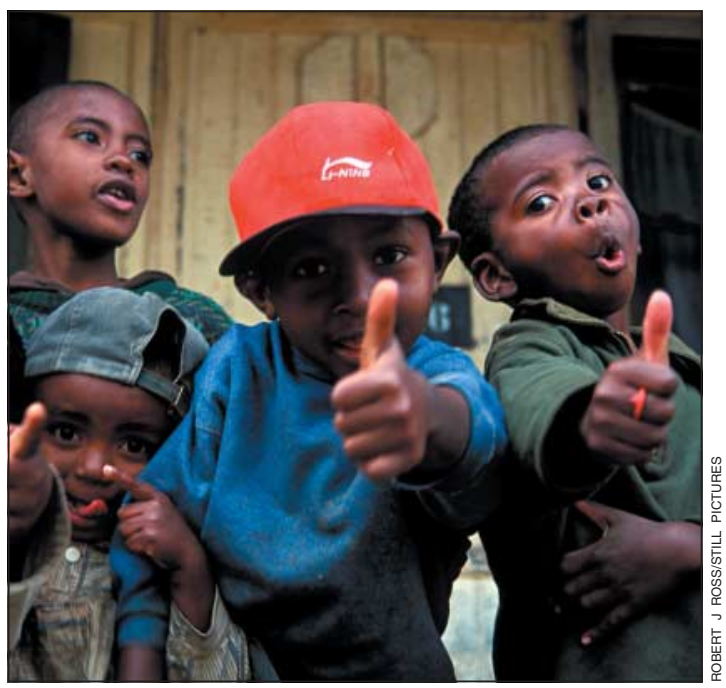

A promising future for health research in Africa 
levels of research funding are increased. The recommendation by the Commission on Health Research for Development that at least $2 \%$ of national health budgets and at least 5\% of development aid should be invested in health research and on building research capacity must be heeded without further delay. ${ }^{14}$

Research with, rather than in or about, Africa is the goal. This will demand joint working to set agendas for research and mutual respect for countries' priorities, values, and choices. Partnerships should be transparent, clearly showing what each side brings and what each stands to gain. Furthermore, there must be clear mechanisms to ensure that some funds for research are directed to strengthening the capacity to conduct research, manage research (by establishing processes to handle grant funding and to review the ethics of proposed research), and develop skills in scientific writing. Finally, Africa's researchers, policy makers, and partners will have to give special attention to ensuring that knowledge generated from research is acted on to improve health for all.

Jimmy Volmink professor and chair of primary health care

Faculty of Health Sciences, University of Cape Town, Groote Schuur Hospital, Observatory 7925, Cape Town, South Africa

(jvolmink@cormack.uct.ac.za)

Lola Dare chief executive officer

Center for Health Sciences Training, Research, and Development International, Ibadan, Nigeria
Competing interests: None declared.

1 Wagner CS, Brahmakulam I, Jackson B, Wong A, Yoda T. Science and technology collaboration: building capacity in developing countries? 2001. nology collaboration: building capacity in developing countries? 2001.
www.rand.org/publications/MR/MR1357.0/ (accessed 23 Sep 2005).

2 www.rand.org/publications/MR/MR 1357.0/ (accessed 23 Sep 2005). (Paper commissioned by the Working Group on Access to Medicines, UN Millennium Project Task Force on HIV/AIDS, Malaria, TB and Access to Essential Medicines. UN Millennium Project, New York, 2004.)

3 World Health Organization. World report on knowledge for better health: strengthening health systems. Geneva: WHO, 2004. www.who.int/rpc/ meetings/en/world_report_on_knowledge_for_better_health2.pdf (accessed 23 Sep 2005).

4 Volmink J, Siegfried N, Robertson K, Gulmezoglu AM. Research synthesis and dissemination as a bridge to knowledge management: the sis and dissemination as a bridge to knowledge management:
Cochrane Collaboration. Bull World Health Organ 2004;82:778-83.

5 Nkuhlu WL. The new partnership for Africa's development: the journey so far.June 2005 http://www.nepad.org/2005/files/documents/journey. pdf

6 Swiss commission for Research Partnership with Developing Countries. Guidelines for research in partnership with developing countries: 12 principles. Berne: Swiss Academy of Sciences, 2000.

7 Costello A, Zumla A. Moving to research partnerships in developing countries. BMJ 2000;321:827-9.

8 Edejer T. North-South research partnerships: the ethics of carrying out research in developing countries. BMJ 1999;319:438-41.

9 Binka F. North-South research collaborations: a move towards true partnership? Trop Med Int Health 2005;10:207-9.

10 United Nations Development Program. Human development report 2005. http://hdr.undp.org/reports/global/2005/ (accessed 23 Sep 2005).

11 Sevene E, Lewin S, Mariano A, Woelk G, Oxman AD, Mantinhure S, et al. System and market failures: the unavailability of magnesium sulphate for the treatment of eclampsia and pre-eclampsia in Mozambique and Zimbabwe. BMJ 2005;331:765-9.

12 Chandramohan D, Owusu-agyei S, Carneiro I, Awine T, AmponsaAchiano K, Mensah N, et al. Cluster randomised trial of intermittent preventive treatment for malaria in infants in area of high, seasonal transmission in Ghana. BMJ 2005;331:727-33.

13 Zurovac D, Ndhlovu M, Rowe AK, Hamer DH, Thea DM, Snow RW. Treatment of paediatric malaria during a period of drug transition to Treatment of paediatric malaria during a period of drug transition to
artemether-lumefantrine in Zambia: cross-sectional study. BMJ artemether-lume

14 Commission on Health Research for Development. Health research: essential link to equity in development. New York: Oxford University Press, 1990.

\title{
Antimalarial treatment with artemisinin combination therapy in Africa
}

\author{
Desirable, achievable, but not easy
}

$\mathrm{T}$ The steady increase of drug resistant malaria across Africa is a crisis for which there are achievable solutions, but no easy ones. The scale of the problem is not in doubt. In Africa malaria remains one of the commonest causes of death and serious morbidity, especially for children and pregnant women. ${ }^{1}$ Despite a decision in principle by many countries in Africa to use artemisinin based combination therapies (ACTs), most cases of malaria are still treated with monotherapy and in many areas most of these treatments will fail. ${ }^{2}$

Drug combinations, rather than monotherapy, are now seen to be the best solution for treating malaria, and artemisinin based drug combinations are highly effective, with cure rates similar to that of chloroquine 30 years ago. They seem to be a good long term choice for most African countries, being safe and well tolerated (with the caveat that their safety in early pregnancy is not yet clear). Compared with other antimalarials, ACTs can reduce gametocyte carriage and thereby lower the risk of infectiousness in those who take treatment. In areas of relatively low malaria transmission in South East Asia and South Africa, widespread use of ACTs has reduced significantly the burden of malaria. ${ }^{4}$ This benefit is likely be less marked in areas of very high transmission in Africa, where much of the reservoir of malaria infection is in asymptomatic people who never seek treatment.

The primary problem with using ACTs in Africa is cost. The least expensive treatment courses currently cost more than $\$ 1$, roughly 10 times that of current monotherapy. In much of the continent people have malaria several times a year, and this cost could be prohibitive both for governments and households. In response to this problem policy makers have made strenuous efforts-led by the Global Fund for HIV/AIDS, Tuberculosis and Malaria-both to increase the supply of artemisinins (alleviating a current global shortage) and to provide drugs to governments at well below their market price.

This has prompted two parallel debates which have not yet been fully resolved. One is among donor agencies on how to achieve a sustainable subsidy. Nobody who understands this issue believes that subsidy can be avoided if ACTs are to reach those who need them most. ${ }^{5}$ What form that subsidy should take is, however, a complex technical matter on which there is no current consensus. Using these drugs will depend on a sustainable stream of funding; ministries of health in Africa are understandably wary of the 